\title{
ДОСЛІДЖЕННЯ ОРГАНІЧНИХ КИСЛОТ У ТРАВІ ТА ПІДЗЕМНИХ OPГAHAX SAPONARIA OFFICINALIS L.
}

Вступ. Мильнянка лікарська (Saponaria officinalis L.) - багаторічна трав'яниста рослина, представник родини гвоздикові (Caryophyllaceae). Вона поширена по всій території Європи, у Північній Африці та на заході до Середньої Азії, але на даний час також культивується в багатьох країнах світу. В Saponaria officinalis L. cпостерігають високий рівень сапонінів, також рослина містить фрлавоноїди, квайлову кислоту, жирні кислоти та різні френольні сполуки. У джерелах літератури є інформація про протигрибкову активність сапонінової фрракції мильнянки лікарської проти Gaeumannomyces graminis var. tritici ŭ Fusarium culmorum та їі антимікробні властивості. Відомостей про хімічний склад первинних метаболітів, а саме органічних кислот, у траві та підземних органах Saponaria officinalis L. у доступній літературі не знайдено, хоча ці речовини є одними з важливих класів природних сполук і мають широкий спектр біологічної та фрармакологічної дій.

Мета дослідження-виявити і визначити методом високоефективної рідинноїхроматографрії (BEPX) кількісний вміст окремих компонентів органічних кислот у траві та кореневищах мильнянки лікарської.

Методи дослідження. Кількісний вміст органічних кислот визначали методом ВЕРХ на рідинному хроматограсрi Agilent 1200 (Agilent Technologies, США).

Результати й обговорення. Методом ВЕРХ у траві мильнянки лікарської ідентифріковано та визначено кількісний вміст винної, піровиноградної, ізолимонної, буритинової і фумарової кислот, у підземних органах - піровиноградної, ізолимонної, лимонної, бурштинової та фрумарової. Серед органічних кислот у траві рослини домінували ізолимонна та піровиноградна кислоти, вміст яких становив 120,83 і 25,14 мг/2 відповідно. У підземних органах Saponaria officinalis L. в найбільшій кількості було визначено бурштинову кислоту (0,79 мг/2).

Висновки. Уперше методом ВЕРХ досліджено якісний склад та кількісний вміст органічних кислот у мильнянці лікарській. Встановлено, що трава і підземні органи досліджуваної рослини містять винну, піровиноградну, ізолимонну, лимонну, фумарову та буритинову кислоти. Серед органічних кислот у траві мильнянки лікарської домінувала ізолимонна кислота, вміст якої становив 120,83 мг/2. У кореневищах досліджуваного об'єкта переважала буритинова кислота (0,79 мг/2). Отримані результати свідчать про перспективність подальших поглиблених фрітохімічних досліджень біологічно активних речовин мильнянки лікарської (Saponaria officinalis L.).

КЛЮЧОВІ СЛОВА: мильнянка лікарська; трава; підземні органи; органічні кислоти; високоесективна рідинна хроматографрія.

ВСТУП. Мильнянка лікарська (Saponaria officinalis L.) - багаторічна трав'яниста рослина, представник родини гвоздикові (Caryophyllaceae). Кореневища в неї повзучі та досить довгі (до 35-40 см), розгалужені й достатньо тонкі, зовні червонувато-бурі (інколи червоні або коричневі). Стебло в мильнянки прямостояче, 35-90 см заввишки, просте, в його верхній частині (іноді й на середині) - округле і гіллясте. Листя супротивне, довгасте, овально-ланцетне або еліптичне, з 3-5 добре помітними жилками. По краях вони шорсткі, з короткими живцями [1].

( ) Л. В. Костишин, Л. В. Слободянюк, С. М. Марчишин, О. Л. Демидяк, Л. Ю. Ляшенко, 2020.
Мильнянка лікарська поширена по всій території Європи, у Північній Африці та на заході до Середньої Азії, але на даний час також культивується в багатьох країнах світу.

У рослині спостерігають високий рівень сапонінів, тому мильнянку лікарську використовують як відхаркувальний засіб, для видалення катару з верхніх дихальних шляхів. Очищена сапонінова фрракція із Saponaria officinalis проявляє гіпохолестеринемічні ефекти in vitro, що, як вважають, зумовлено здатністю сапоніну утворювати нерозчинний комплекс із холестерином [2]. 
Окрім сапонінів, Saponaria officinalis L. містить фрлавоноїди, квайлову кислоту, жирні кислоти та різні фенольні сполуки [3]. G. M. Petrović та ін. встановили, що пагони мильнянки лікарської містять ефрірну олію, основними компонентами якої $€$ фітол, трикозан-6,8-діон, спирт пачулі та трикозан, тоді як спирт пачулі, генейкозан і трикозан домінують в ефрірній олії з квіток цієї рослини [4].

У джерелах літератури $є$ інфрормація про наявність протигрибкової активності в сапонінової фрракції мильнянки лікарської проти Gaeumannomyces graminis var. tritici й Fusarium culmorum та її антимікробні властивості. Припускають, що екстракти, одержані з цієї рослини, можуть бути використані як природні консерванти у срармацевтичній та харчовій промисловості [5].

Відомостей про хімічний склад первинних метаболітів, а саме органічних кислот, у траві та підземних органах Saponaria officinalis L. у доступній літературі не знайдено, хоча ці речовини $€$ одними з важливих класів природних сполук і мають широкий спектр біологічної та фрармакологічної дій. Відомо, що органічні кислоти беруть участь у процесі обміну речовин, активізують роботу слинних залоз, стимулюють роботу шлунково-кишкового тракту, проявляють бактерицидну, антимікробну, протизапальну активність [6, 7].

Мета дослідження - виявити і визначити методом високоефективної рідинної хроматограсрії (BEPX) кількісний вміст окремих компонентів органічних кислот у траві та кореневищах мильнянки лікарської.

МЕТОДИ ДОСЛІДЖЕННЯ. Об'єктамИ дЛЯ досліджень були трава та кореневища мильнянки лікарської. Траву заготовляли у фазу масового цвітіння рослини на території Чернівецької області, підземні органи - після відмирання надземної частини.

Компонентний склад органічних кислот досліджували методом ВЕРX [8] на рідинному хроматограсрі Agilent 1200 (Agilent Technologies, США). Як рухому фразу використовували ацетонітрил (А) та 0,1 \% розчин $\mathrm{H}_{3} \mathrm{PO}_{4}$ у воді (B) (1:99). Елюювання проводили в ізократичному режимі.
Для розділення застосовували хроматограсрічну колонку Zorbax SB-Aq (4,6 мм \pm 150 мм, 3,5 мкм) (Agilent Technologies, США). Швидкість потоку через колонку - 0,5 мл/хв, температура термостата $-30{ }^{\circ} \mathrm{C}$, об'єм інжекції - 3 мкл. Детекцію проводили з використанням діодно-матричного детектора з реєстрацією сигналу при 210 нм та фріксацією спектрів поглинання в діапазоні 210-700 нм [9].

Підготовка проб для аналізу: наважку досліджуваної сировини кожної проби (0,2-1,0 г) екстрагували в 5 мл 0,1\% розчину $\mathrm{H}_{3} \mathrm{PO}_{4}$ на ультразвуковій бані при $80{ }^{\circ} \mathrm{C}$ упродовж 4 год у скляних герметичних віалах із тесрлоновою кришкою. Отриманий екстракт центрифугували при 3 тис. об./хв та фрільтрували крізь одноразові мембранні фрільтри з порами 0,22 мкм.

Ідентифікацію та кількісний аналіз проводили з використанням стандартних розчинів органічних кислот (винної, піровиноградної, ізолимонної, лимонної, бурштинової, яблучної, щавлевої).

Вміст сполук (X) (мг/г) визначали за фрормулою:

$$
\mathrm{X}=\mathrm{c} \cdot \mathrm{V} /(\mathrm{m} \cdot 1000),
$$

де с - концентрація сполуки, визначена хроматограсрічно, мкг/мл;

$\mathrm{V}$ - об'єм екстракту, мл;

$\mathrm{m}$ - маса сировини, з якої проводили екстракцію, г;

1000 - коесріцієнт перерахунку мкг у мг.

РЕЗУЛЬТАТИ Й ОБГОВОРЕННЯ. МЕТОДОМ ВEPX у траві мильнянки лікарської ідентифіковано та визначено кількісний вміст винної, піровиноградної, ізолимонної, бурштинової і фумарової кислот, у підземних органах - піровиноградної, ізолимонної, лимонної, бурштинової та фумарової. Результати визначення компонентного складу органічних кислот мильнянки лікарської наведено в таблиці, а хроматограми органічних кислот у траві та кореневищах досліджуваного об'єкта - на рисунках 1 і 2.

Серед органічних кислот у траві мильнянки лікарської домінували ізолимонна та піровиноградна кислоти, вміст яких становив 120,83 та

Таблиця - Кількісний вміст органічних кислот у траві та підземних органах мильнянки лікарської

\begin{tabular}{||l|c|c|c||}
\hline \hline \multicolumn{1}{|c|}{ БАР } & Час утримування, хв & $\begin{array}{c}\text { Кількісний вміст у траві, } \\
\text { мг/г }\end{array}$ & $\begin{array}{c}\text { Кількісний вміст } \\
\text { уореневищах, мг/г }\end{array}$ \\
\hline Винна кислота & 1.930 & 0,26 & $\mathrm{H} / \mathrm{B}$ \\
\hline Піровиноградна кислота & 2.299 & 25,14 & 0,07 \\
\hline Ізолимонна кислота & 2.436 & 120,83 & 0,02 \\
\hline Лимонна кислота & 3.004 & $\mathrm{H} / \mathrm{B}$ & 0,19 \\
\hline Бурштинова кислота & 3.198 & 10,95 & 0,79 \\
\hline Фумарова кислота & 4.631 & 0,04 & 0,02 \\
\hline \hline
\end{tabular}

Примітка. н/в - не виявлено. 


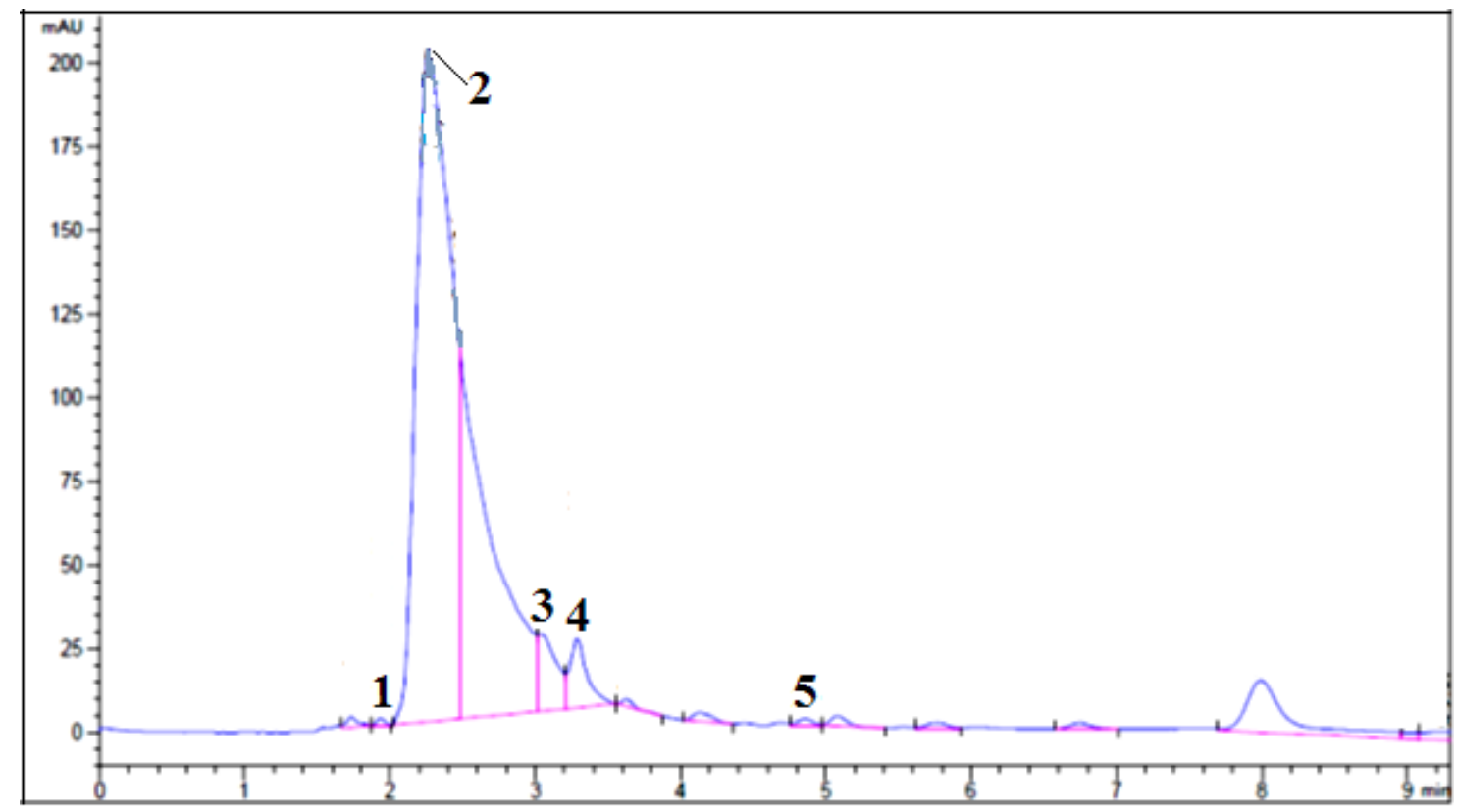

Pис. 1. BEPX-хроматограма органічних кислот у траві Saponaria officinalis L.: 1 - винна, 2 - піровиноградна, 3 ізолимонна, 4 - бурштинова, 5 - фрумарова кислоти.

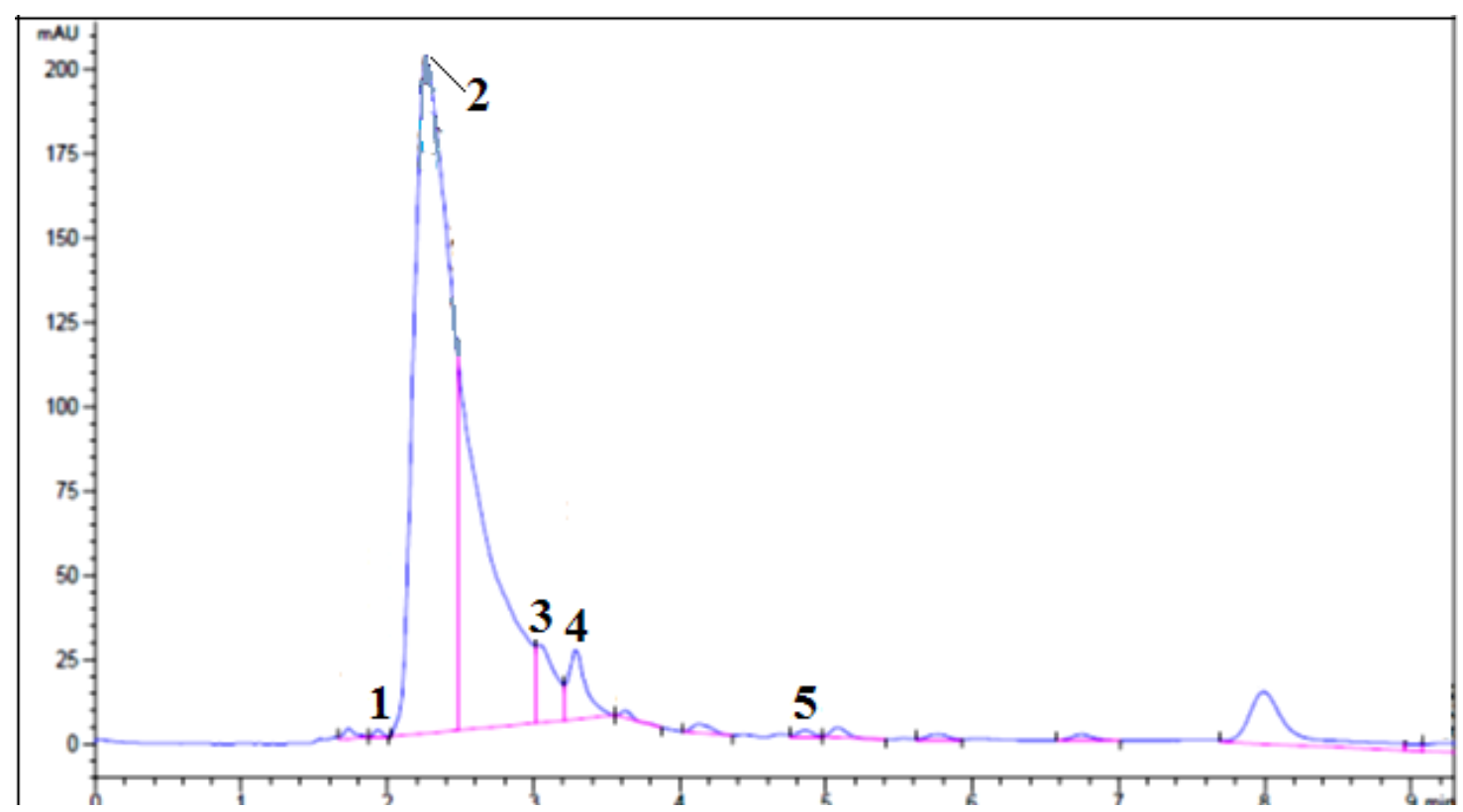

Рис. 2. ВЕРX-хроматограма органічних кислот у підземних органах Saponaria officinalis L.: 1 - піровиноградна, 2 ізолимонна, 3 - лимонна, 4 - бурштинова, 5 - фумарова кислоти.

25,14 мг/г відповідно. У підземних органах Saponaria officinalis L. у найбільшій кількості було визначено бурштинову кислоту (0,79 мг/г).

У траві мильнянки лікарської не виявлено лимонної кислоти, а у кореневищах - винної.

Як видно 3 таблиці, мильнянка лікарська синтезує винну, піровиноградну, ізолимонну, лимонну, бурштинову і фумарову кислоти, що $€$ каталізаторами біохімічних процесів та активаторами тканинного дихання як у рослинних, так і тваринних організмах [10].
Отримані результати становлять основу для подальшого хімічного і фрармакологічного дослідження мильнянки лікарської та будуть враховані під час розробки методів контролю якості при стандартизації цієї рослинної сировини.

ВИСНОВКИ. 1. Уперше методом ВЕРХ досліджено якісний склад та кількісний вміст органічних кислот у мильнянці лікарській. Встановлено, що трава і підземні органи досліджуваної рослини містять винну, піровиноградну, ізоли- 
монну, лимонну, фрумарову та бурштинову кислоти.

2. Серед органічних кислот у траві мильнянки лікарської домінувала ізолимонна кислота, вміст якої становив 120,83 мг/г. У кореневищах

\section{СПИСОК ЛІТЕРАТУРИ}

1. Cherevach E. I. Justification of Saponaria officinalis (S. officinalis) cultivation in the soil and climatic conditions of the Primorsky region (Russia) and analysis of saponincontaining root extracts / E. I. Cherevach, R. K. Shchekaleva // Journal of Central European Agriculture. 2020. - No. 21 (2). - P. 420-430.

2. New triterpenoid saponins from the roots of Saponaria officinalis / B. Moniuszko-Szajwaj, Ł. Pecio, M. Kowalczyk [et al.] // Natural Product Communications. - 2013. - No. 8 (12). - P. 1687-1690.

3. Antiproliferative quillaic acid and gypsogenin saponins from Saponaria officinalis L. roots. / Y. Lu, D. Van, L. Deibert [et al.] // Phytochemistry. - 2015. - No. 113. P. $108-120$

4. Phytochemical analysis of Saponaria officinalis $L$. shoots and flowers essential oils. / G. M. Petrović, M. D. Ilić, V. P. Stankov-Jovanović [et al.] // Natural Product Research. - 2018. - No. 32 (3). - P. 331-334.

5. Effect of triterpenoid saponins of field scabious, alfalfa, red clover and common soapwort on growth of Gaeumannomyces graminis var. tritici and Fusarium culmorum. / J. Czaban, J. Mołdoch, B. Wróblewska [et al.] // Allelopathy Journal. - 2013. - No. 32. - P. 79-90. досліджуваного об'єкта переважала бурштинова кислота $(0,79$ мг/г).

3. Отримані результати свідчать про перспективність подальших поглиблених фрітохімічних досліджень біологічно активних речовин мильнянки лікарської (Saponaria officinalis L.).
6. Опрошанська Т. В. Кількісний вміст суми органічних кислот у серіях сировини деяких представників родин Polygonaceae, Rosaceae та Asteraceae / Т. В. Опрошанська, О. П. Хворост, В. В. Кудря // Мед. та клініч. хімія. - 2020. - 22, № 3 (85). - С. 81-86.

7. Analysis of organic acids of tricarboxylic acid cycle in plants using GC-MS, and system modeling / Kumar Vinod, Sharma Anket, Bhardwaj Renu, Kumar Thukr Ashwani // Journal of Analytical Science and Technology. - 2017. - No. 8. - P. 20.

8. Analysis of carboxylic acids of Crambe cordifolia Steven / S. Marchyshyn, L. Slobodianiuk, L. Budniak, O. Skrynchuk // Pharmacia. - 2021. - No. 68 (1). P. 15-21.

9. Quantification of sugars and organic acids in tomato fruits / C. Agius, S. von Tucher, B. Poppenberger, W. Rozhon. - MethodsX, 2018. - 5. - P. 537-550.

10. Верещагин А. Л. О механизме ростостимулирующего действия сверхмалых доз природных органических кислот / А. Л. Верещагин, В.В.Кропоткина, А. Н. Хмелева // Вестн. Алтайского государственного аграрного университета. - 2006. - № 1. - С. 46-48.

\section{REFERENCES}

1. Cherevach, E.I., \& Shchekaleva, R.K. (2020). Justification of Saponaria officinalis (S. officinalis) cultivation in the soil and climatic conditions of the Primorsky region (Russia) and analysis of saponin- containing root extracts. Journal of Central European Agriculture, 21 (2), 420-430.

2. Moniuszko-Szajwaj, B., Pecio, Ł., Kowalczyk, M., Simonet, A.M., Maciasb, F.A., Szumacher-Strabel, M., Cieślak, A., Oleszek, W., \& Stochmal, A. (2013). New triterpenoid saponins from the roots of Saponaria officinalis. Natural Product Communications, 8 (12), 16871690.

3. Lu, Y., Van, D., Deibert, L., Bishop, G., \& Balsevich, J. (2015). Antiproliferative quillaic acid and gypsogenin saponins from Saponaria officinalis L. roots. Phytochemistry, 113, 108-120.

4. Petrović, G.M., llić, M.D., Stankov-Jovanović, V.P., Stojanović, G.S., \& Jovanović, S.Č. (2018). Phytochemical analysis of Saponaria officinalis L. shoots and flowers essential oils. Natural Product Research, 32 (3), 331-334.
5. Czaban, J., Mołdoch, J., Wróblewska, B., Szumacher-Strabel, M., Cieślak, A., Oleszek, W., \& Stochmal, A. (2013). Effect of triterpenoid saponins of field scabious, alfalfa, red clover and common soapwort on growth of Gaeumannomyces graminis var. tritici and Fusarium culmorum. Allelopathy Journal, 32, 79-90.

6. Oproshanksa, T.V., Khvorost, O.P., \& Kudria, V.V. (2020). Kilkisnyi vmist sumy orhanichnykh kyslot u seriiakh syrovyny deiakykh predstavnykiv rodyn Polygonaceae, Rosaceae ta Asteraceae [Quantitative content of the sum of organic acids in the series of raw materials of some members of the families Polygonaceae, Rosaceae and Asteraceae]. Medychna ta klinichna khimiia Medical and Clinical Chemistry, 22 (3), 81-86 [in Ukrainian].

7. Kumar Vinod, Sharma Anket, Bhardwaj Renu, \& Kumar Thukral Ashwani (2017). Analysis of organic acids of tricarboxylic acid cycle in plants using GC-MS, and system modeling. Journal of Analytical Science and Technology, 8, 20. 
8. Marchyshyn, S., Slobodianiuk, L., Budniak, L., \& Skrynchuk, O. (2021) Analysis of carboxylic acids of Crambe cordifolia Steven. Pharmacia, 68 (1), 15-21.

9. Agius, C., von Tucher, S., Poppenberger, B., \& Rozhon, W. (2018) Quantification of sugars and organic acids in tomato fruits. Methods $X, 5,537-550$.

10. Vereshhagin, A.L., Kropotkina, V.V., \& Khmeleva, A.N. (2006) O mekhanizme rostostimuliruyushhego deystviya sverkhmalykh doz prirodnykh organicheskikh kislot [On the mechanism of growth-stimulating action of ultra-low doses of natural organic acids]. Vestnik Altayskogo gosudarstvennogo agrarnogo universiteta Altai State Agrarian University Bulletin, 1, 46-48 [in Russian].

Л. В. Костышин, Л. В. Слободянюк, С. М. Марчишин, О. Л. Демидяк, Л. Ю. Ляшенко ТЕРНОПОЛЬСКИЙ НАЦИОНАЛЬНЫЙ МЕДИЦИНСКИЙ УНИВЕРСИТЕТ ИМЕНИ И. Я. ГОРБАЧЕВСКОГО МОЗ УКРАИНЫ

\section{ИССЛЕДОВАНИЕ ОРГАНИЧЕСКИХ КИСЛОТ В ТРАВЕ И ПОДЗЕМНЫХ ОРГАНАХ SAPONARIA OFFICINALIS L.}

\section{Резюме}

Вступление. Мыльнянка лекарственная (Saponaria officinalis L.) - многолетнее травянистое растение, представитель семейства гвоздичные (Caryophyllaceae). Она распространена по всей территории Европы, в Северной Африке и на западе до Средней Азии, но в настоящее время также культивируется во многих странах мира. B Saponaria officinalis L. наблюдают высокий уровень сапонинов, также растение содержит фрлавоноиды, квайловую кислоту, жирные кислоты и различные френольные соединения. В источниках литературы есть информация о противогрибковой активности сапониновой фрракции мыльнянки лекарственной против Gaeumannomyces graminis var. tritici u Fusarium culmorum и ее антимикробных свойствах. Сведений о химическом составе первичных метаболитов, а именно органических кислот, в траве и подземных органах Saponaria officinalis L. в доступной литературе не найдено, хотя эти вещества являются одними из важных классов природных соединений и обладают широким спектром биологического и фрармакологического действий.

Цель исследования - выявить и определить методом высокоэффективной жидкостной хроматограсрии (ВЭЖХ) количественное содержание отдельных компонентов органических кислот в траве и корневищах мыльнянки лекарственной.

Методы исследования. Количественное содержание органических кислот определяли методом ВЭЖХ на жидкостном хроматографре Agilent 1200 (Agilent Technologies, США).

Результаты и обсуждение. Методом ВЭЖХ в траве мыльнянки лекарственной идентифрицировано и определено количественное содержание винной, пировиноградной, изолимонной, янтарной и фрумаровой кислот, в подземных органах - пировиноградной, изолимонной, лимонной, янтарной и фумаровой. Среди органических кислот в траве растения доминировали изолимонная и пировиноградная кислоты, содержание которых составляло 120,83 и 25,14 мг/2 соответственно. В подземных органах Saponaria officinalis L. в самом большом количестве была определена янтарная кислота (0,79 мг/2).

Выводы. Впервые методом ВЭЖХ исследованы качественный состав и количественное содержание органических кислот в мыльнянке лекарственной. Установлено, что трава и подземные органы исследуемого растения содержат винную, пировиноградную, изолимонную, лимонную, фумаровую и янтарную кислоты. Среди органических кислот в траве мыльнянки лекарственной доминировала изолимонная кислота, содержание которой составляло 120,83 мг/2. В корневищах исследуемого объекта преобладала янтарная кислота (0,79 мг/2). Полученные результаты свидетельствуют о перспективности дальнейших углубленных фритохимических исследований биологически активных веществ мыльнянки лекарственной (Saponaria officinalis L.).

КЛЮЧЕВЫЕ СЛОВА: мыльнянка лекарственная; трава; подземные органы; органические кислоты; высокоэффрективная жидкостная хроматография. 


\section{STUDY OF ORGANIC ACIDS IN HERB AND UNDERGROUND ORGANS OF SAPONARIA OFFICINALIS L.}

\section{Summary}

Introduction. Soapwort (Saponaria officinalis L.) is a perennial herbaceous plant belonging to the CaryophyIlaceae family. Soapwort is distributed throughout Europe, North Africa and west to Central Asia, but is now also cultivated in many countries around the world. Saponaria officinalis L. has a high content of saponins, and also contains flavonoids, quailic acid, fatty acids and various phenolic compounds. The literature sources contain data on the antifungal activity of the saponin fraction of soapwort against Gaeumannomyces graminis var. tritici and Fusarium culmorum, and antimicrobial properties. Information on the chemical composition of primary metabolites, namely organic acids, in hetb and underground organs of Saponaria officinalis $L$. is not found in the available literature, although these substances are one of the important classes of natural compounds and have a wide range of biological and pharmacological action.

The aim of the study - to identify and quantify by HPLC the individual components of organic acids in the herb and rhizomes of soapwort.

Research Methods. The content of organic acids was determined by HPLC on a liquid chromatograph Agilent 1200 (Agilent Technologies, USA).

Results and Discussion. The quantitative content of tartaric, pyruvic, isolimonic, succinic and fumaric acids was identified and established by HPLC in the herb of the soapwort, and pyruvic, isolimonic, citric, succinic and fumaric acids in the underground organs. Among the organic acids in the herb of soapwort, the dominant components were isolimonic and pyruvic acids, the content of which was $120.83 \mathrm{mg} / \mathrm{g}$ and $25.14 \mathrm{mg} / \mathrm{g}$, respectively. Succinic acid $(0.79 \mathrm{mg} / \mathrm{g})$ was found in the largest amount in the underground organs of Saponaria officinalis $L$.

Conclusions. For the first time, the qualitative composition and quantitative content of organic acids in soapwort were studied by HPLC. It was found that the herb and underground organs of the studied plant contain tartaric, pyruvic, isolimonic, citric, fumaric and succinic acids. The dominant component among organic acids in the herb of soapwort was isolimonic acid, the content of which was $120.83 \mathrm{mg} / \mathrm{g}$. Succinic acid $(0.79 \mathrm{mg} / \mathrm{g})$ predominated in the rhizomes of the study object. The obtained results indicate the prospects of further in-depth phytochemical studies of biologically active substances of soapwort (Saponaria officinalis L.).

KEY WORDS: Saponaria officinalis; herb; underground organs; organic acids; HPLC.

Отримано 17.11.20

Адреса для листування: С. М. Марчишин, Тернопільський національний медичний університет імені І. Я. Горбачевського моз України, майдан Волі, 1, Тернопіль, 46001, Україна, e-mail: marchyshyn@tdmu.edu.ua. 